\title{
Patients' perception of cancer-related fatigue: results of a survey to assess the impact on their everyday life
}

\author{
Nieves Díaz · Salvador Menjón • Christian Rolfo • Pilar García-Alonso · Joan Carulla • Ana Magro • \\ José Miramón · César A. Rodríguez · Rous de Castellar · José A. Gasquet
}

Received: 14 June 2008 / Accepted: 25 July 2008

\begin{abstract}
Purpose Fatigue is a cancer-related symptom with great impact on patients' daily lives, but often not discussed with
\end{abstract}

\author{
N. Díaz \\ H. San Juan de Alicante \\ Alicante, Spain \\ S. Menjón \\ $\mathrm{H}$. Virgen de las Nieves \\ Granada, Spain \\ C. Rolfo \\ Clínica Rotger \\ Palma de Mallorca, Spain \\ P. García-Alfonso \\ H. Gregorio Marañón \\ Madrid, Spain \\ J. Carulla \\ H. Gral. Matéu Orfila \\ Menorca, Spain \\ A. Magro \\ H. Francesc Borja \\ Gandía, Spain \\ J. Miramón \\ H. de Ronda \\ Ronda, Spain \\ C.A. Rodríguez \\ H. Universitario de Salamanca \\ Salamanca, Spain \\ R. de Castellar ( $\triangle)$ \\ 3D Health Research \\ Pza. Tetuán, $41 \mathrm{pl} 1$ of 19 \\ ES-08010 Barcelona, Spain \\ e-mail: rdecastellar@3d-hr.com -info@3d-hr.com
}

\section{J.A. Gasquet}

Amgen S.A.

Barcelona, Spain their oncologists. This survey explored functional and psychological fatigue impact among different cancer symptoms according to patient's perception (pp).

Methods A cross-sectional, self-administered survey was conducted in 10 oncologist services throughout Spain. Demographical data and tumour diagnoses were collected. Fatigue impact on functional and social activities (Likert scale) and on emotional well-being (visual analogue scale) was measured. The pp of oncologist's response to fatigue report was recorded.

Results 505 surveyed cancer patients were analysed (55.2\% women, aged 58.8 years \pm 11.7 ), $97.8 \%$ remembered experiencing fatigue during treatment. $27.1 \%$ did not discuss their fatigue with their oncologist. Fatigue affected patient's daily routine ( $\geq 50 \%$ of times) included self-care (58.26\%), entertainment activities (69.8\%), and relationships (71.4\%). Fatigue was the most bothersome symptom of cancer.

Conclusions Cancer patients perceive fatigue as the symptom with highest impact on their daily living and that substantially affects their emotional and social areas.

Keywords Quality of life · Fatigue · Cancer · Outcome assessment $\cdot$ Patient-professional relations

\section{Introduction}

Fatigue is a complex, multifactor disorder that affects the physical and psychological wellbeing of cancer patients and, therefore, cancer-related fatigue (CRF) has been associated with significant impairment of patients' quality of life [1].

Most patients with CRF feel unable to lead a normal life [2] and have to limit their social activities and family relationships. Fatigue has an even deeper impact on their quality of life than other symptoms such as pain, depression and nausea [3-5]. 
Two US surveys conducted by the Fatigue Coalition [6] documented the high prevalence of fatigue in patients suffering from cancer $(76-78 \%)[7,8]$, but perhaps the most notable outcome was the disagreement in fatigue perception between patients and oncologists $(61 \%$ of the patients felt that their daily living was more affected by fatigue than by cancer-related pain, while only $37 \%$ of oncologists believed that this was the patient's situation). Almost all patients felt that CRF was a significant emotional component that contributed to perceiving a more serious loss of control and the inability to lead a normal life, which often provoked feelings of sadness, frustration, motivation loss and mental exhaustion [9]. This emotional impact, mentioned above, has been corroborated by numerous studies [10-12].

Moreover, an improvement in the management of fatigue may lead to an improvement in cancer-provoked psychological disturbances such as depression or anxiety [13].

As there are no Spanish studies on this, this survey was designed with the aim of better understanding how Spanish patients perceive their disease-related fatigue. The purpose of this investigation was to examine how patients assess fatigue impact on their moods, personal activities and social relationships, and the fatigue load in relation to other cancer symptoms according to the patient's perception (pp).

\section{Material and methods}

\section{Design}

A cross-sectional multi-centre survey was conducted from August to October 2007 in 10 medical oncology departments throughout Spain. Each survey contained written instructions and clearly specified that the filling out of the form was both voluntary and confidential. Responses were handwritten by patients in the oncologist waiting room and were not supervised during the completion and return of the survey.

\section{Patients}

Respondents anonymously completed this self-administered survey. Eligible patients were $\geq 18$ years of age, having cancer diagnosis and their last treatment regimen (radiotherapy and/or chemotherapy) between 2 and 12 months before completing the survey. Patients with dementia or any other serious mental illness that prevented survey comprehension were excluded.

\section{Survey}

The survey instrument consisted of 12 items. Data on demographic and clinical characteristics were collected for statistical purposes.

The survey included a $10-\mathrm{mm}$ visual analogue scale (VAS) to measure the fatigue impact on emotional wellbe- ing during cancer treatment (anchored by two extremes: from ' 0 '=not at all to ' 100 '=very much). The survey also included 3 questions regarding fatigue impact on daily living activities, including functional and social activities, each one rated on a 5 -point Likert scale (from ' 5 '=always to ' 0 '=never).

Two additional questions gathered the pp of the fatigue treatment decision-making process. Patients were asked if they discussed the fatigue treatment with their physician, and if they had received any treatment for reducing fatigue.

Finally, patients were asked to fill out a check-list with the 3 side effects or symptoms that most affected their daily living (ranking from $1=$ the most bothersome to $3=$ the third one) among 10 side effects/symptoms: anxiety, fatigue, anorexia, hair loss, depression, diarrhoea, pain, constipation, sleep disturbances, weight loss and nausea/vomiting.

\section{Statistical analyses}

Descriptive statistics were used to summarise demographic data and survey responses. Absolute frequencies were presented for categorical data, and mean and standard deviation (SD) were used for quantitative data. Additional descriptive analyses were performed grouping patients by sex or by cancer type.

All patients who had returned a completed survey were included in the analysis set. The statistics were generated using a standard statistical package (SPSS for Windows, version 13.0, SPSS Inc, Chicago, IL, USA).

\section{Results}

\section{Clinical characteristics}

527 completed questionnaires were returned from 10 centres and 505 respondents were included in the evaluable analysis set; $55.2 \%$ of them were women and the median age was 60 years (range 28-87). The most prevalent tumours were located in breast $(26.5 \%)$, gastrointestinal (20.8\%) and lung (14.5\%). $77.0 \%$ of patients had undertaken chemotherapy, $1.4 \%$ radiotherapy and $21.4 \%$ both (with and without other additional treatment) (Table 1).

\section{Fatigue prevalence}

97.8\% of the patients remembered experiencing fatigue during the course of their cancer treatment at least once (80.2\% at least $50 \%$ of the time) (Table 2).

\section{Patients' perception of fatigue management}

$72.9 \%$ of surveyed patients reported that they discussed fatigue treatments with their physicians. $61.2 \%$ of the pa- 
Table 1 Patients' characteristics

\begin{tabular}{llll}
\hline & Total $(n=505)$ & Men $(n=226)$ & Women $(n=279)$ \\
\hline Gender (\%) & & 44.8 & 55.2 \\
Age (years): mean (SD) & $58.8(1.7)$ & $61.5(10.8)$ & $56.7(12.0)$ \\
Type of cancer \% (n) & & & \\
Breast & $26.5(134)$ & - & $48.0(134)$ \\
Gastrointestinal & $20.8(105)$ & $23.9(54)$ & $18.3(51)$ \\
Lung & $14.5(73)$ & $25.2(57)$ & $5.7(16)$ \\
Prostate & $8.3(42)$ & $18.6(42)$ & - \\
Leukaemia/lymphoma & $8.1(41)$ & $8.0(18)$ & $8.2(23)$ \\
Bladder/kidney/genitourinary & $6.1(31)$ & $7.5(17)$ & $5.0(14)$ \\
Head/neck & $6.7(34)$ & $12.8(29)$ & $1.8(5)$ \\
Gynaecologic & $8.1(41)$ & - & $14,7(41)$ \\
Unknown & $2.4(12)$ & $5.3(12)$ & - \\
Type of treatment ${ }^{\mathrm{a}}$ & & & \\
Chemotherapy & $98.4(497)$ & $98.2(222)$ & $98.6(275)$ \\
Radiotherapy & $22.8(115)$ & $19.0(43)$ & $25.8(72)$ \\
Surgery & $27.5(139)$ & $17.3(39)$ & $35.8(100)$ \\
$\quad$ Others & $2.6(13)$ & $2.7(6)$ & $2.5(7)$ \\
Number of treatments: mean (SD) & $1.5(0.76)$ & $1.4(0.6)$ & $1.6(0.9)$ \\
\hline
\end{tabular}

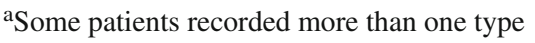

Table 2 Characteristics of fatigue: prevalence and impact on emotional wellbeing

\begin{tabular}{llll}
\hline & Total $(n=505)$ & Men $(n=226)$ & Women $(n=279)$ \\
\hline How often did you feel fatigue during the treatment?: \% (n) & $100.0(504)$ & $100.0(225)$ & $100.0(279)$ \\
$\quad$ Always & $4.4(22)$ & $3.6(8)$ & $5.0(14)$ \\
Many times & $26.2(132)$ & $29.8(67)$ & $23.3(65)$ \\
50\% of the times & $49.6(250)$ & $44.4(100)$ & $53.8(150)$ \\
Hardly ever & $17.3(87)$ & $19.1(43)$ & $15.8(44)$ \\
Never & $2.6(13)$ & $3.1(7)$ & $2.2(6)$ \\
Fatigue impact on emotional well-being: VAS mean (SD) & $54.9(19.2)$ & $55.5(19.5)$ & $54.4(19.0)$ \\
\hline
\end{tabular}

tients remembered receiving some treatment for fatigue reduction. $16.8 \%$ of those who asked for some treatment reported that nothing was recommended by the oncologist.

\section{Fatigue impact}

The impact of fatigue on emotional wellbeing showed a mean on the VAS of 54.87 (SD: 19.2). At least $50 \%$ of the time, $58.3 \%$ of patients informed that fatigue limited their self-care activities (washing self, dressing or undressing self, etc.); $69.8 \%$ also reported that fatigue affected their leisure activities (walking, shopping, going to a movie, etc.) and in $71.4 \%$ of the patients, fatigue prevented them from conducting social activities with friends and relatives (Fig. 1).

Fatigue was remembered by patients as the most bothersome cancer symptom or side effect. $63.4 \%$ of the patients identified it as the first-, second- or third-ranking symptom from a list of the 10 most frequent cancer-related symptoms. In patients grouped according to sex or tumour type, fatigue remained the symptom that most affected their daily lives during treatment (Table 3).

\section{Discussion}

To our knowledge these is the first data about fatigue prevalence and impact in cancer patients within the Spanish population. These findings are consistent with those of previous studies conducted in other countries.

A higher percentage of patients than other epidemiological studies $[3,6,7]$ reported receiving some treatment to reduce fatigue. This pattern of findings must be viewed in light of the study's methodology limitations. The study relied on self-administered surveys and did not consider numerous variables possibly important in providing a thorough understanding regarding CRF management. Furthermore, this study did not assess different types of prescribed measures for reducing fatigue such as medication (erythropoietic agents, iron and vitamin supplements, etc.) or lifestyle recommendations. Despite these methodological limitations, research suggests that fatigue is remembered by patients as the most bothersome cancer symptom. In this study, fatigue was found as the main symptom in the ranking of disabling cancer symptoms. It even rises far above the second most annoying symptom, anxiety. 


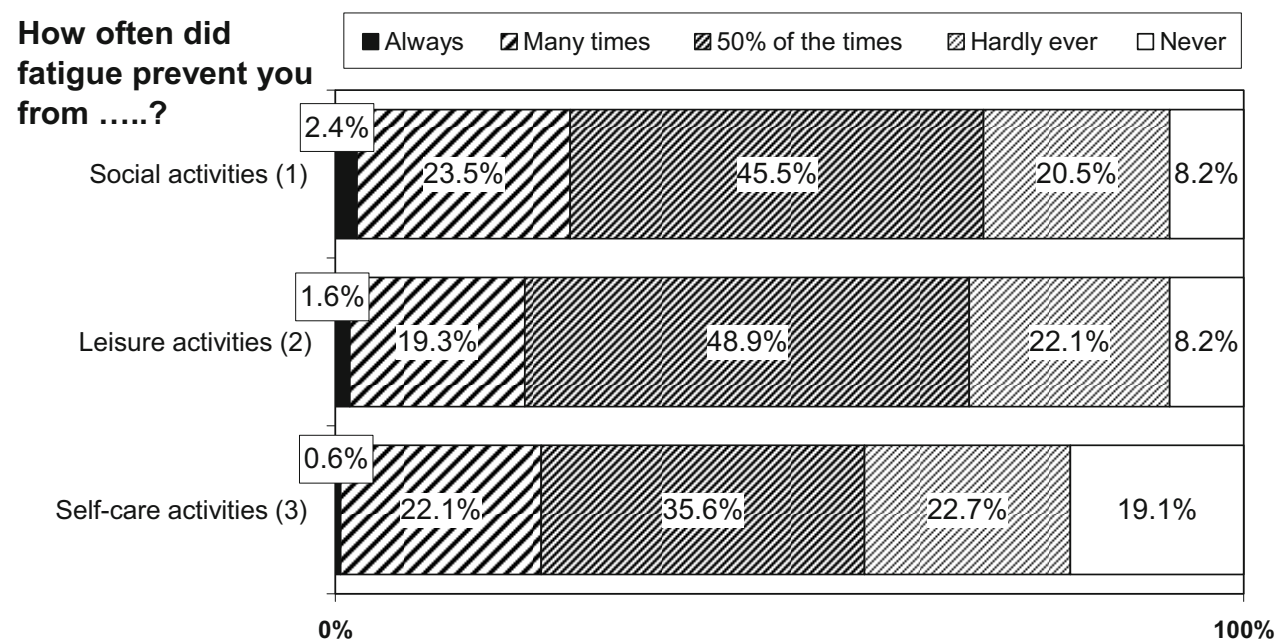

Fig. 1 Impact of fatigue on patient's daily living $(N=505)$

(1): spending time with family members, friends, or neighbours, playing with children, participating in family parties, etc. (2): walking, shopping, going to a movie or a restaurant, etc. (3): washing self, dressing/undressing self, etc

Although the data were not confirmed by statistical tests, the results suggest differences between genders in the assessment of symptoms. There are few research studies on gender differences in cancer-related pain, fatigue and depression. No differences were found either in pain or in fatigue, but prevalence rates for depression were higher in women [14]. The assessment of cancer symptoms has subjective components linked to gender, psychological and social aspects [15-17]. Even so, fatigue remained the most limiting cancer side effect or symptom for both genders.
Pain has traditionally been the most evaluated symptom and therefore the most treated by physicians [18], probably because it has ceased to be a concern for most patients. Our data, along with those from similar studies, suggest the need for health professionals to take into account the psychological and social impact of inadequate fatigue management [19].

An objective quantification of fatigue impact on cancer patients is not easy. This can be limiting for a fair assessment by the oncologist [20]. In this respect, it would be

Table 3 Impact of fatigue relative to other side effects/symptoms by sex or by tumour

\begin{tabular}{|c|c|c|c|c|}
\hline \multirow{2}{*}{$\begin{array}{l}\text { "Rank the three symptoms that you remember } \\
\text { affecting your daily life the most }\end{array}$} & \multicolumn{4}{|c|}{ Symptoms rank ${ }^{\mathrm{a}}$ by sexes } \\
\hline & Total $(n=505)$ & \multicolumn{2}{|c|}{$\operatorname{Men}(n=226)$} & Women $(n=279)$ \\
\hline Fatigue & 1 st $(63.4 \%)$ & 1 st $(60$ & & 1 st $(65.6 \%)$ \\
\hline Anxiety & 2nd $(49.9 \%)$ & $3 \mathrm{rd}(48$ & & 2nd $(51.3 \%)$ \\
\hline Sleep disturbances & $3 \mathrm{rd}(36.0 \%)$ & 2 nd $(4$ & & - \\
\hline Nausea/vomiting & 4th $(29.5 \%)$ & - & & - \\
\hline Anorexia & 5 th $(29.1 \%)$ & - & & - \\
\hline Depression & 6th $(28.7 \%)$ & - & & - \\
\hline Hair loss & 7 th $(28.3 \%)$ & - & & $3 r d(42.7 \%)$ \\
\hline \multirow{2}{*}{$\begin{array}{l}\text { "Rank the three symptoms that you remember } \\
\text { affecting your daily life the most" }\end{array}$} & \multicolumn{4}{|c|}{ Symptoms rank ${ }^{\mathrm{a}}$ by tumour type $\mathrm{e}^{\mathrm{b}}$} \\
\hline & Total $(n=505)$ & Breast $(n=134)$ & Lung ( $n=73)$ & Gastrointestinal $(n=105)$ \\
\hline Fatigue & $1 \mathrm{st}$ & 1 st $(62.2 \%)$ & 1 st $(83.6 \%)$ & 1 st $(58.1 \%)$ \\
\hline Anxiety & 2nd & 2 nd $(54.5 \%)$ & 2nd $(56.2 \%)$ & - \\
\hline Sleep disturbances & $3 \mathrm{rd}$ & - & 3rd $(43.8 \%)$ & 3 rd $(42.9 \%)$ \\
\hline Nausea/vomiting & 4 th & - & - & - \\
\hline Anorexia & 5 th & - & - & 2nd $(47.6 \%)$ \\
\hline Depression & 6th & 3 rd $(21.9 \%)$ & - & - \\
\hline
\end{tabular}

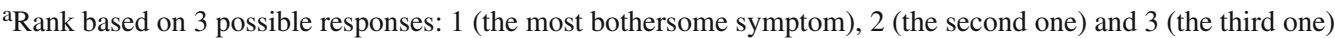

${ }^{\mathrm{b}} \mathrm{A}$ patient could refer to more than 1 tumour type 
necessary to have some psychometric tools to assist the physician in measuring fatigue severity to provide a better understanding of the clinical implications of fatigue and make its management more appropriate.
Acknowledgements This survey has been conducted under the auspices of the Spanish Society of Medical Oncology (SEOM) and supported by an unrestricted educational grant from Amgen S.A., Barcelona, Spain.

\section{References}

1. Portenoy RK, Itri LM (1999) Cancer-related fatigue: guidelines for evaluation and management. Oncologist 4:1-10

2. Hofman M, Ryan JL, Figueroa-Moseley CD et al (2007) Cancer-related fatigue: the scale of the problem. Oncologist 12:4-10

3. Curt GA, Breitbart W, Cella D et al (2001) Impact of cancer-related fatigue on the lives of patients: new findings from the Fatigue Coalition. In: Marty M, Pecorelli S (eds) Fatigue and cancer. Elsevier, Amsterdam, pp 3-16

4. Stone P, Richardson A, Ream E et al (2000) Cancer-related fatigue: inevitable, unimportant and untreatable? Results of a multi-centre patient survey. Cancer Fatigue Forum. Ann Oncol 11:971-975

5. Vogelzang NJ, Breitbart W, Cella D et al (1997) Patient, caregiver, and oncologist perceptions of cancer-related fatigue: results of a tripart assessment survey. The Fatigue Coalition. Semin Hematol 34[3 Suppl 2]:4-12

6. Curt GA (2000) The impact of fatigue on patients with cancer: overview of FATIGUE 1 and 2. Oncologist 5:9-12

7. Hofman M, Morrow GR, Roscoe JA et al (2004) Cancer patients' expectations of experiencing treatment-related side effects: a University of Rochester Cancer Center-Community Clinical Oncology Program study of 938 patients from community practices. Cancer 101:851-857

8. Lawrence DP, Kupelnick B, Miller K et al (2004) Evidence report on the occurrence, assessment, and treatment of fatigue in cancer patients. J Natl Cancer Inst Monogr 32:40-50

9. Curt GA, Breitbart W, Cella D et al (2000) Impact of cancer-related fatigue on the lives of patients: new findings from the Fatigue Coalition. Oncologist 5:353-360

10. Dimeo F, Stieglitz RD, Novelli-Fischer U et al (1999) Effects of physical activity on the fatigue and psychologic status of cancer patients during chemotherapy. Cancer 85:2273-2277

11. Stone P, Richards M, A'Hern R, Hardy J (2000) A study to investigate the prevalence, severity and correlates of fatigue among patients with cancer in comparison with a control group of volunteers without cancer. Ann Oncol 11:561-567

12. Henry D, Viswanathan H, Wade SM et al (2006) The patient's experience of fatigue: a cross-sectional study of cancer patients. 48th Annual Meeting of the American Society of Hematology, Orlando, Florida [Abstract 3356]

13. Tchekmedyian NS, Kallich J, McDermott A et al (2003) The relationship between psychologic dis- tress and cancer-related fatigue. Cancer 98:198203

14. Miaskowski C (2004) Gender differences in pain, fatigue, and depression in patients with cancer. J Natl Cancer Inst Monogr 32:139-143

15. Monteiro-Grillo I, Marques-Vidal P, Jorge M (2005) Psychosocial effect of mastectomy versus conservative surgery in patients with early breast cancer. Clin Transl Oncol 11:499-503

16. Katz MR, Irish JC, Devins GM et al (2003) Psychosocial adjustment in head and neck cancer: the impact of disfigurement, gender and social support. Head Neck 25:103-112

17. Parker PA, Baile WF, de Moor C, Cohen L (2003) Psychosocial and demographic predictors of quality of life in a large sample of cancer patients. Psychooncology 12:183-193

18. Conroy JM, Harvey SC (1996) Management of cancer pain. South Med J 89:744-760

19. Patrick DL, Ferketich SL, Frame PS et al (2004) National Institutes of Health State-of-the-Science Conference Statement: symptom management in cancer: pain, depression, and fatigue, July 15-17, 2002. J Natl Cancer Inst Monogr 32:9-16

20. Curt G, Johnston PG (2003) Cancer fatigue: the way forward. Oncologist 8[Suppl 1]:27-30 